\title{
ABRINDO OS OLHOS SOBRE A DITADURA MILITAR: AUDIODESCRIÇÃO COMO RECURSO DE MANUTENÇÃO DA MEMÓRIA BRASILEIRA
}

\author{
Lucinéa Marcelino Villela* \\ Universidade Estadual Paulista Júlio de Mesquita Filho \\ Célio José Losnak ${ }^{* *}$ \\ Universidade Estadual Paulista Júlio de Mesquita Filho
}

\begin{abstract}
Resumo: Em 2014, a sociedade brasileira teve a oportunidade de debater o triste período da Ditadura depois dos 50 anos do Golpe Militar. O objetivo principal deste artigo é a apresentação de um projeto de audiodescrição com fotos e vídeos marcantes da ditadura brasileira e seus reflexos na sociedade brasileira. O projeto foi elaborado pelo grupo de pesquisa Mídia Acessível e Tradução Audiovisual, cujo foco principal é produzir recursos de acessibilidade para produtos audiovisuais diferentes (audiodescrição e legendas). Produzimos um foto-documentário com um panorama de algumas imagens importantes e com um roteiro com enfoque em informações sobre a política brasileira de 1964 a 1989. Foram seguidas diversas etapas
\end{abstract}

\footnotetext{
* Lucinéa Marcelino Villela: Doutora (2004) em Comunicação e Semiótica pela Pontifícia Universidade Católica de São Paulo (PUC-SP). Mestre (1997) em Linguística Aplicada pela Universidade Estadual de Campinas (Unicamp). Professora do curso de Radialismo da Faculdade de Arquitetura, Artes e Comunicação da Universidade Estadual Paulista Júlio de Mesquita Filho, campus Bauru. Bauru, São Paulo, Brasil. E-mail: lucinea@rocketmail.com

** Célio José Losnak: Doutor (2000) e Mestre (1993) em História Social pela Universidade de São Paulo. Licenciado (1985) em História pela Universidade Estadual Paulista Júlio de Mesquita Filho (Unesp). Professor do curso de Radialismo da Faculdade de Arquitetura, Artes e Comunicação da Universidade Estadual Paulista Júlio de Mesquita Filho, campus Bauru. Bauru, São Paulo, Brasil. E-mail: losnak@ faac.unesp.br
} 
durante o processo de produção: a seleção das fotos, a contextualização histórica, os roteiros, a locução e a edição final do vídeo. A fim de produzir os roteiros das audiodescrições das fotos e das imagens selecionadas, seguimos algumas premissas sobre o processo de produção acessível. De acordo com Matamala (2006:330), os audiodescritores devem possuir várias competências, tais como: "the ability to undertake intersemiotic translations (turning images into words), the ability to summarise information in order to adapt the text to the limited space available, keeping the original meaning, by means of rewording and by using synonyms; the ability to critically select the most relevant information".

Palavras-chave: Acessibilidade. Audiodescrição. Ditadura brasileira. Tradução audiovisual.

\title{
OPENING THE EYES ABOUT DICTATORSHIP: AUDIO DESCRIPTION AS A RESOURCE OF BRAZILIAN MEMORY'S MAINTENANCE
}

\begin{abstract}
In 2014 the Brazilian society had the opportunity to debate the harsh period of its dictatorship after 50 years since the 1964 Military Coup. The main goal of this paper is the presentation of an Audio Description project with remarkable photos and videos from Brazilian Dictatorship and its reflections on Brazilian society. The project was elaborated by the research group "Accessible Media and Audiovisual Translation", whose main focus is provide accessibility (audio description and subtitles) for different audiovisual products. We produced a photo documentary with an overview of some important images and with a script focusing on important information about Brazilian politics from 1964 up to 1989. Many steps were followed during the whole process: selection of photos, historical contextualization, script, narration, final editing of the video. In order to produce the audio description scripts of photos and images selected, we have followed some assumptions about audio description. According to Matamala (2006:330) various competences are required to audio describers such as: "the ability to undertake intersemiotic translations (turning images into words), the ability to summarise information in order to adapt the text to the limited space available, keeping the original meaning, by means of rewording and by using synonyms; the ability to critically select the most relevant information".
\end{abstract}

Keywords: Accessibility. Audiovisual Translation. Audio description. Brazilian Dictatorship. 


\section{Introdução}

O ano de 2014 foi marcado por diversos debates e reflexões sobre os 50 anos do início da Ditadura Militar no Brasil. Várias palestras, relatos e entrevistas de ex-exilados, militares aposentados e familiares de ativistas foram apresentados no ambiente acadêmico, bem como na mídia em geral, com o intuito não somente de relembrar um triste período da história brasileira, mas principalmente de trazer novamente à tona as injustiças cometidas pelo governo militar durante cerca de vinte longos anos, incluindo prisões ilegais, torturas que culminaram em mortes completamente perversas e outras atrocidades.

As iniciativas de pesquisadores comprometidos com a temática e de defensores dos Direitos Humanos não se iniciaram e nem se esgotaram nesse período, mas foi necessária e imprescindível a intensificação desse debate na sociedade, justamente em um momento em que são ouvidas declarações levianas em manifestações populares sobre a volta da Ditadura no Brasil. Tal postura nos leva a refletir que tem ocorrido um retrocesso político e ideológico em nosso país.

Um projeto importante e inovador para o país nos últimos anos foi a Comissão Nacional da Verdade ${ }^{1}$. Apesar das críticas aos seus limites, ela apresentou resultados que repercutiram na mídia, atingindo o grande público, e pôs em evidência alguns responsáveis por mortes e torturas, inspirou inúmeras outras comissões em nível estadual, municipal e em instituições, como as universidades, demonstrando o gradativo amadurecimento democrático da sociedade brasileira ao conseguir conviver com o desvendar de memórias silenciadas e que, quando emersas, explicitam responsabilidades não invalidadas pelo passar do tempo, apesar de nem sempre serem judicialmente punidas.

Esse cenário instigou o Grupo de Pesquisas Mídia Acessível e Tradução Audiovisual ${ }^{2}$ (MATAV) para que, além de refletir so-

\footnotetext{
${ }^{1}$ Com os resultados e documentos acessíveis por http://www.cnv.gov.br/

${ }^{2}$ O Grupo de Pesquisa MATAV é cadastrado pelo CNPq desde 2013 e é liderado
} 
bre a temática, produzisse um foto-documentário com recursos de acessibilidade intitulado "A Ditadura militar na perspectiva dos deficientes visuais" 3 . A proposta do produto audiovisual acessível para pessoas com deficiência visual foi apresentar um breve panorama sobre o período que vai de 1964, início “oficial” da Ditadura, até as eleições indiretas em 1989.

Neste artigo apresentaremos primeiramente os conceitos sobre a audiodescrição advindos da área de Tradução Audiovisual (MOTTA, s.d.; BENECKE, 2004), verificaremos dois estudos sobre a recepção de $\mathrm{AD}$ realizados no Brasil e, em seguida, faremos uma análise histórica sobre o foto-documentário. Na terceira parte do artigo focaremos nas etapas de elaboração de um produto audiovisual acessível e nossas conclusões.

\title{
Audiodescrição aplicada a produtos audiovisuais
}

O pesquisador alemão Bernd Benecke (2004), considera a audiodescrição como:

\begin{abstract}
[...] a técnica usada para tornar acessível produções teatrais, cinematográficas e programas de TV para pessoas cegas e com deficiência visual: uma narração adicional descreve a ação, a linguagem corporal, expressões faciais, cenários e figurino. A descrição se encaixa entre o diálogo e não interfere com características marcantes do áudio e dos efeitos sonoros. (BENECKE, 2004, p. 2, tradução nossa)
\end{abstract}

pela Profa. Dra. Lucinéa Marcelino Villela, docente do Departamento de Ciências Humanas da Faculdade de Arquitetura, Artes e Comunicação da UNESP, Bauru.

${ }^{3}$ Foto-documentário disponível no canal do YOUTUBE do Grupo MATAV https://www.youtube.com/watch?v=R75LjPCPUng . 
Para que ocorra a inserção da $\mathrm{AD}$ em produtos audiovisuais, deve-se analisar suas cenas, enredo e escolher com precisão em quais intervalos deverão ser inseridas as descrições, segundo critérios de priorização de alguns elementos em detrimento de outros.

Segundo Benecke (2004), o processo de roteirização de audiodescrição deve sempre ser feito em equipe, com consultor com deficiência visual para que atenda de forma eficaz o público-alvo. Ele menciona algumas etapas desse processo: a) escolha dos programas televisivos adequados (alguns possuem diálogos muito rápidos, fator que dificulta a inserção de $\mathrm{AD}$ ); b) elaboração de um roteiro provisório; c) ajuste do nível do áudio do programa.

Lívia Motta (s.d), por sua vez, conceitua a audiodescrição da seguinte maneira:

\begin{abstract}
A Audiodescrição é uma atividade de mediação linguística, uma modalidade de tradução intersemiótica, que transforma o visual em verbal, abrindo possibilidades maiores de acesso à cultura e à informação, contribuindo para a inclusão cultural, social e escolar. Além das pessoas com deficiência visual, a audiodescrição amplia também o entendimento de pessoas com deficiência intelectual, idosos e disléxicos.
\end{abstract}

Concordamos com a postura da autora ao defender que a AD pode ampliar o entendimento de um signo visual não somente para as pessoas com deficiência visual, mas também para o público-alvo idoso, disléxicos e, inclusive, para os videntes que não têm a completa percepção de alguns elementos visuais ao assistirem um filme, uma peça ou para contemplarem uma obra artística.

Alguns projetos brasileiros sobre a recepção de produtos audiovisuais com AD desenvolvidos desde o final da década de 1990 já apresentaram resultados bastante relevantes como protocolo a ser seguido. Apresentaremos as propostas de pesquisadoras de Salvador e de Brasília que possuem em comum a preocupação em ter seus materiais testados pelos próprios usuá- 
rios e, dessa forma, estabelecer os parâmetros adequados para cada região do Brasil.

Um estudo bastante detalhado sobre a recepção de audiodescrição foi apresentado no artigo "Confronting amateur and academic audiodescription: a Brazilian case study”, elaborado pelas pesquisadoras Eliana Franco, Sandra R. Rosa Farias, Íris Fortunato e Manoela Cristina da Silva (2011). As autoras apresentam resultados de pesquisa feita pelo Grupo de Pesquisa TRAMAD. Suas produções audiovisuais para o público com deficiência visual foram avaliadas em três diferentes instituições ${ }^{4}$ e após observar e tabular as várias reações dos receptores, as pesquisadoras puderam constatar que as preferências sobre o conteúdo das ADs são muito locais e constataram que, ao contrário do modelo europeu, os receptores avaliados preferem o maior número de descrições possíveis, mesmo que sejam elementos desconhecidos por eles.

Segundo as autoras,

Portanto, o modelo brasileiro de audiodescrição baseado na pesquisa de recepção feita com nossos participantes deve incluir não somente uma descrição verbal detalhada das imagens, mas também a explicação de itens culturais ou específicos quando for necessário (FRANCO et al, 2011, p. 3. Tradução nossa)

Outra pesquisa com receptores de audiodescrição para cinema foi realizada por Soraya Ferreira Alves, Veryanne Couto Teles e Tomás Verdi Pereira (2011), pesquisadores da Universidade de Brasília (UnB). Os autores realizaram com sua equipe as ADs de quatro curtas-metragens de diretores brasilienses seguindo dois modelos: espanhol (centrado na ação, vocabulário simples e frases coordenadas curtas) e o inglês (audiodescrição detalhada do cená-

${ }^{4}$ Associação Baiana de Cegos, Laramara e Dorina Nowill. 
rio e das características físicas dos personagens, utilização de gama variada de adjetivos e vocabulário rebuscado).

Assim como Benecke (2004), os pesquisadores da UnB ressaltam a importância do trabalho em equipe em uma $\mathrm{AD}$ de qualidade: roteirista de $\mathrm{AD}$, narrador, consultor com deficiência visual e técnico de som.

Os participantes da pesquisa relataram que as ADs muito detalhadas causavam confusões durante a apresentação dos filmes, por outro lado, destacaram a importância da descrição de elementos como características dos personagens, dos ambientes e do tempo. Ou seja, queriam detalhes das imagens.

Anna Matamala e Pilar Orero (2007), pesquisadoras da Universidade Autónoma de Barcelona, defendem que a formação do audiodescritor deva ser feita em ambiente acadêmico. Uma das propostas das autoras é que haja uma disciplina de audiodescrição em Programas de Mestrado em Tradução Audiovisual ou em Cursos de Especialização em Tradução Audiovisual.

De acordo com as autoras:

Treinar pessoas para compreender, observar e implementar acessibilidade é o objetivo primordial da maioria dos cursos de mídia acessível. As áreas de ensino superior nas quais a acessibilidade midiática e a audiovisual têm sido implementadas fazem parte de cursos de várias áreas (telecomunicação, engenharia, ciência da computação, jornalismo, pedagogia e tradução) que focam em diferentes aspectos dependendo de seus interesses (questões técnicas ou de conteúdo). (MATAMALA; ORERO, 2007, p.5. Tradução nossa)

De forma geral, consideramos que devido à necessidade da implantação de recursos acessíveis em tantos meios de comunicação e entretenimento, tais disciplinas podem ser implantadas para cursos de diversas áreas de conhecimento, tais como Tradução, Comunicação, Cinema, Artes, Radialismo etc. 


\section{História e Memória da Ditadura}

O foto-documentário que foi produzido pelo grupo MATAV percorre momentos importantes do período, entre a renúncia de Jânio Quadros, a subsequente posse de João Goulart, o movimento pelas eleições diretas e a posse de Sarney como presidente civil, apesar de ter sido eleito indiretamente.

Centrando em questões políticas relevantes, a narração reconstrói uma panorâmica articulando movimentações reivindicativas da sociedade civil e ações dos governos militares, reprimindo oposições e conduzindo propostas autoritárias. $\mathrm{O}$ mérito do produto audiovisual elaborado pelo MATAV é o de manter o tema na memória social, despertar curiosidade e indignação, principalmente dentre as gerações mais novas, instigar indagações e suscitar reflexões sobre o golpe, efetuado com a justificativa de defender a democracia ${ }^{5}$ e que se perpetuou nas décadas seguintes por via autoritária e violência armada.

A narrativa audiovisual apresenta uma história acontecida, mas a compreensão do período é perpassada por uma história interpretativa, é recortada por textos com objetivos políticos e acadêmicos que fizeram parte da militância e contribuíram para elucidar as amarras impostas à sociedade pela ditadura. As produções iniciais, ainda nos anos 1970, eram realizadas por agentes envolvidos no processo. Obras de denúncia, como por exemplo, contra a tortura (CAVALCANTI; RAMOS, 1978) e de revelações dos bastidores do poder (ABREU, 1979) visavam à intervenção na política do momento. A imprensa denominada de alternativa canalizou interessados na publicação de informações que se contrapunham ao silêncio, às versões oficiais e à autocensura dos grandes veículos de comunicação (KUCINSKI, 1991; SMITH, 2000).

A partir do final da década, difundiram-se relatos memorialísticos sobre a trajetória da militância armada, informando ao público

${ }^{5}$ Esse foi o principal argumento da época e reproduzido posteriormente pelos militares (D’ARAUJO, 1994). 
ávido por conhecimento daquilo que fora censurado, ao mesmo tempo em que os autores avaliavam a trajetória passada e indagavam sobre erros e acertos apostando em novos direcionamentos políticos para aquele momento (CARDOSO, 1994) ${ }^{6}$.

No mesmo período, livros produzidos por jornalistas também atuaram na investigação, esclarecimento e divulgação de eventos e atores importantes, propondo leituras, alimentando polêmicas e dialogando com memórias de militantes e versões oficiais. Nesse âmbito, destacamos livros-reportagem sobre a morte de Wladimir Herzog (JORDÃO, 1979), a Guerrilha do Araguaia (PORTELA, 1979), os movimentos políticos de jovens no ano de 1968 (VENTURA, 1988), a militância política dos dominicanos e a relação deles com a repressão e com Marighela (BETTO, 1991). Além dos depoimentos memorialísticos, essas obras jornalísticas de grande público foram as primeiras que atenderam à curiosidade dos leitores, no período com relativa liberdade de publicação, entre 1979 e 1984, e alimentaram a certeza da necessidade de distanciamento do passado autoritário que se consolidava na segunda metade da década.

Um desdobramento dessa tendência culminou com a elaboração e promulgação da constituição cidadã de 1988, ainda hoje uma referência importante na área de direitos humanos e sociais.

Nos anos 1980, a academia produziu análises variadas sobre o golpe, enfatizando questões e abordagens diferenciadas, ora priorizando o protagonismo das forças econômicas, ou as organizações de segmentos civis, a fragilidade institucional do país, conflitos e incertezas do governo Goulart, ou ainda a tradição golpista dos militares (FICO, 2004) ${ }^{7}$. Alguns pontos vão ficando mais claros

${ }^{6}$ Dois destaques com perspectivas diferentes do passado são: Fernando Gabeira (1980), lançado em 1979, e Alfredo Sirkis (1988), com primeira edição em 1980. Esses livros foram sucedidos por vários outros, memórias e reportagens apresentando interpretações diferenciadas do passado e legitimando alguns agentes em detrimento de outros. Cardoso (1994) fez um balanço dessas obras e mostrou o caráter polêmico e multifacetado delas.

${ }^{7}$ Dentre inúmeras fontes possíveis, opto por citar algumas mais clássicas de autores que se debruçaram com perspectivas diferenciadas. Bandeira (1983) 
à medida que aumenta o distanciamento temporal e as análises se despem dos fortes vínculos vividos. Não havia tão rígida separação entre Estado e Sociedade. Embora o golpe tenha sido realizado pelos militares, os civis se organizaram contra João Goulart, reivindicaram apoio para interromper as movimentações populares, dos grupos de esquerda, dos nacionalistas e petebistas (NAPOLITANO, 2011). A grande imprensa intensificou veiculação de críticas ao governo, saudou o golpe e, durante anos, manteve apoio aos militares (LOSNAK, 2005).

As forças armadas não se constituíam em um grupo homogêneo, tinham visões diferentes sobre o tempo a permanecer no poder, sobre as estratégias de enfrentamento das oposições e de aproximação dos segmentos civis. Os grupos e partidos de esquerda fragmentavam-se em inúmeras tendências e concentravam membros oriundos das classes médias (RIDENTI, 1993). Apesar do autoritarismo, segmentos sociais significativos apoiaram a ditadura, principalmente os setores empresariais e a classe média que foram os principais beneficiados pelo crescimento econômico enquanto as classes populares sofreram alto índice de exploração (FURTADO, 1981; SINGER, 1982). A tortura também teve apoio dos civis. A Operação Bandeirantes (OBAN), aparato investigativo e repressivo sediado em São Paulo, recebeu financiamento de empresários.

enfatizou a mobilização dos EUA e dos grandes conglomerados econômicos para depor João Goulart e contando com os seguimentos civis nacionais. Dreifuss (1987) demonstrou a mobilização das grandes corporações internacionais e de empresas nacionais, aliados a intelectuais e políticos, no movimento de gestão do golpe. Alves (1984) apresenta a força da Ideologia de Segurança Nacional na articulação do golpe como estratégia de defesa diante da ameaça comunista e fragilidade das forças armadas diante de desestabilizações internas infiltradas pela política e do processo de oposição à ditadura, liderado pela sociedade civil organizada, que teria desencadeado a abertura política. Sader (1988) percorreu os movimentos sociais dos anos 1970 como agentes importantes na mobilização contra o autoritarismo e que contribuíram para o fortalecimento da sociedade civil. 
Em 2014, ano de produção do foto-documentário em pauta, novos balanços bibliográficos emergiram. Inúmeros eventos buscaram amadurecer as reflexões, esmiuçar análise e detalhar temas (NAPOLITANO et al., 2014).

Vale ressaltar que o gênero de produto proposto é inédito na academia brasileira no que se refere à temática da Ditadura no Brasil, o que demonstra que as diversas áreas de conhecimento (Estudos Audiovisuais, Estudos da Tradução, História, Ciências Políticas etc) podem e devem se unir no interesse de manter viva a história de seu país.

\section{Processo de audiodescrição de foto-documentário sobre 50 anos Ditadura no Brasil}

O foto-documentário foi realizado pelos membros do Grupo de Pesquisa MATAV em um processo que durou cerca de três meses entre concepção do produto, roteiro histórico e da $\mathrm{AD}$, consultorias com profissionais, locuções e edição final (março a maio de 2014).

Na primeira reunião sobre o produto, os componentes do grupo optaram para analisar as fotos do período de 1964 até 1989, tendo em vista que há imagens amplamente divulgadas e bastante marcantes que representam historicamente o início, meio e fim da Ditadura Militar no Brasil. Infelizmente tais fotos ainda não estão em domínio público, o que inviabiliza a apresentação delas neste trabalho, mas pudemos utilizá-las por meio do canal do YOUTUBE.

As fotos escolhidas apresentam as seguintes situações: renúncia de Jânio Quadro, início do governo de João Goulart, Marcha da Família com Deus pela Liberdade, os primeiros atos que institucionalizaram o Golpe Militar, assinatura do AI5, as manifestações contra a Ditadura, Copa de 1970 no México, chegada da seleção brasileira com a taça do campeonato mundial, fotos do jornalista Wladimir Herzog, celebração da Anistia, atentado no Rio Centro, manifestações em prol das "Diretas Já", fotos da posse de Tancredo Neves e de José Sarney. Várias delas foram apresentadas ao 
longo dos 14 minutos do foto-documentário, mas apenas 11 foram escolhidas para serem audiodescritas:

1. Discurso de João Goulart

2. Manifestação contra o presidente João Goulart

3. Tanques de guerra em frente ao Congresso Nacional

4. Assinatura do ato institucional número 5 (AI5)

5. Foto de Kombi da polícia incendiada por manifestantes contra a Ditadura

6. Recepção da seleção brasileira com o presidente Emílio Médici

7. Presidente Médici com a taça da Copa de 1970 nas mãos

8. Corpo de Wladimir Herzog dentro da cela do DOI/CODI

9. Comemoração da Comissão pela Anistia

10. Atentado no Rio Centro

11. Comício pelas Diretas Já

As razões que justificaram as escolhas tanto das fotos que compuseram o vídeo como um todo, bem como das 11 que foram audiodescritas, estão relacionadas ao fato de estarem disponíveis nos sites de notícias e educacionais (UOL Educação e Instituto Wladimir Herzog), fonte de pesquisa dos componentes do grupo de pesquisa (MATAV).

Além do processo de roteirização da audiodescrição que será detalhado a seguir, houve a escolha da trilha sonora do produto. Nessa etapa, a líder do grupo de pesquisa auxiliou os alunos com sugestões de canções que marcaram todo o período da Ditadura e o final dessa fase. As músicas escolhidas foram: Alegria, Alegria (Caetano Veloso), Roda Viva (Chico Buarque), Cálice (Chico Buarque e Gilberto Gil), Pra frente Brasil (Miguel Gustavo), O bêbado e a equilibrista (João Bosco), Pra não dizer que não falei das flores (Geraldo Vandré), Apesar de você (Chico Buarque), Menestrel de Alagoas (Milton Nascimento).

A preparação do roteiro de audiodescrição foi feita em várias reuniões. Os componentes se dividiram em duplas para escolherem 
fotos que representavam os fatos históricos de cada quatro ou cinco anos. Em seguida, houve reuniões para escolher as imagens com melhor resolução e que também possuíam elementos que fossem facilmente descritos.

Após escolher as 11 fotos em preto e branco que representavam fatos marcantes desde 1964 até 1989, o roteiro de AD foi realizado com intuito de focar personagens e cenários históricos. Quando a relevância era dada a pessoas/protagonistas do período referido, a $\mathrm{AD}$ focava de forma bastante objetiva as características físicas dos envolvidos. Como quase todas as fotos estavam em preto e branco (escolhemos tal efeito propositalmente), as descrições levaram em conta vestimentas, tamanho e tipo de cabelo, postura da pessoa na foto e em relação a outras pessoas presentes na mesma foto.

A seguir o exemplo da audiodescrição da foto do Presidente João Goulart e da primeira dama Maria Thereza. A foto é emblemática pelo fato de mostrar o então Presidente João Goulart defendendo reformas em seu discurso diante de 200 mil pessoas no Centro do Rio de Janeiro.

NO CENTRO DA FOTO/ JOÃO GOULART E SUA ESPOSA/ MARIA THEREZA, ESTÃO EM UM PALANQUE/ //

ELE ESTÁ DE FRENTE PARA UM MICROFONE E DISCURSA COM O DEDO INDICADOR DA MÃO DIREITA PARA CIMA//

JOÃO GOULART VESTE UM TERNO ESCURO//

À ESQUERDA ESTÁ SUA ESPOSA MARIA THEREZA//

O CABELO DELA ESTÁ PRESO EM UM COQUE E TEM UMA FRANJA LATERAL//

MARIA THEREZA USA UM VESTIDO ELEGANTE DE MANGA LONGA E OLHA PARA BAIXO//

ATRÁS DA PRIMEIRA DAMA VEMOS UM SENHOR QUE USA ÓCULOS E OLHA PARA BAIXO E À DIREITA//

À DIREITA DA IMAGEM / VEMOS PARTE DO ROSTO DE UM HOMEM QUE OLHA PARA FRENTE// (trecho da audio- 
descrição do foto-documentário disponível em https://www.youtube.com $/$ watch? $\mathrm{v}=\mathrm{R} 75 \mathrm{LjPCPUng}$ )

Não há na descrição nenhuma apresentação de adjetivos que determinem os sentimentos do presidente e sua esposa, o receptor ouvirá os elementos que são necessários na foto (características físicas das pessoas presentes na foto), os quais por sua vez são complementos da narração histórica que a precedeu. Buscamos seguir nessa tarefa as orientações dadas em artigos das pesquisadoras FRANCO et al (2011).

Outra audiodescrição de personagem político extremamente relevante foi a de Wladimir Herzog dentro da cela do DOIC-CODI. Talvez tenha sido a audiodescrição mais debatida e revisada na produção do foto-documentário, pois na primeira versão do roteiro havíamos inserido o adjetivo "enforcado" na $\mathrm{AD}$, como tal fato sabidamente foi uma montagem feita na época pelos militares, retiramos o termo "enforcado" e colocamos: "Herzog está com uma corda no pescoço amarrada na grade branca de uma janela com vidros quadrados".

Outra mudança importante realizada no roteiro de AD dessa foto foi na ordem de descrição dos elementos na imagem. Na primeira versão descrevemos os elementos que se encontravam no primeiro plano da foto, como a porta e a carteira, mas após apresentarmos o produto para as audiodescritoras Mimi Aragón e Kemi Oshiro (OVNI Acessibilidade, Porto Alegre), trocamos a ordem dos elementos e iniciamos a $\mathrm{AD}$ com a descrição de Wladimir Herzog, pois nesse contexto todos os outros elementos tornam-se coadjuvantes. Segue a AD completa da foto.

FOTOGRAFIA DO JORNALISTA VLADIMIR HERZOG DENTRO DE UMA CELA//

NO FUNDO DA CELA ESTÁ VLADIMIR HERZOG// ELE É PARCIALMENTE CALVO, TEM PELE CLARA E ESTÁ COM 
O CABELO PRETO DESARRUMADO / O MACACÃO, O SAPATO E AS MEIAS QUE O HOMEM ESTÁ VESTINDO SÃO ESCUROS

HERZOG ESTÁ COM UMA CORDA NO PESCOÇO AMARRADA NA GRADE BRANCA DE UMA JANELA COM VIDROS QUADRADOS E SUPORTE BRANCO//

SEUS PÉS TOCAM O CHÃO E SEUS JOELHOS ENCONTRAM-SE DOBRADOS//

A PORTA DA CELA ESTÁ ABERTA E É DE COR CLARA // HÁ UMA CADEIRA ESCOLAR COM APOIO PARA DESTRO/ A CADEIRA POSSUI GRADES INFERIORES PRÓPRIAS PARA COLOCAR CADERNOS//

O CHÃO É ESCURO E COMPOSTO DE PEQUENOS RETÂNGULOS//

Essa foto do jornalista Wladimir Herzog além de ter sido divulgada em diversos jornais, também faz parte do documentário Vlado- Trinta anos depois, dirigido e roteirizado por João Batista de Andrade (2006). O documentário foi disponibilizado pelo Instituto Vladimir Herzog no canal do YOUTUBE http://vladimirherzog. org/vlado-trinta-anos-depois.

\section{Conclusões}

Nossa proposta ao criar o foto-documentário acessível sobre os 50 anos da Ditadura Militar no Brasil foi o de registrar momentos importantes desse período e despertar nos participantes do grupo de pesquisa MATAV (a maioria dos membros cursa Rádio e TV na UNESP) o interesse pela produção de roteiros acessíveis de documentários.

Na maioria das vezes, os roteiristas e diretores não preveem a inserção das legendas, das audiodescrições e nem mesmo da dublagem na concepção de seus produtos audiovisuais. Tanto Chaume 
(2004) quanto Romero-Fresco (2013) propõem o estudo colaborativo das duas áreas: Estudos da Tradução, Cinema \& Audiovisual.

Romero-Fresco (2013) apresenta sua proposta "idealista":

Do ponto de vista da pesquisa e do ensino, a produção de cinema acessível implica em uma troca entre os Estudos de Produção Cinematográfica e a Tradução Audiovisual, na qual os docentes e alunos de Produção Cinematográfica aprendem sobre os aspectos de Tradução Audiovisual e da Acessibilidade que podem contribuir na elaboração e na recepção de (seus) próprios filmes, enquanto os docentes e alunos de Tradução Audiovisual exploram os elementos dos Estudos e da Produção Cinematográfica que podem contribuir para a teoria e a prática da tradução e da acessibilidade. (ROMERO-FRESCO, 2013, p.211. Tradução nossa)

A junção de áreas complementares como Tradução Audiovisual e Produção Cinematográfica só corroboram a ideia de que, para que seja completamente eficaz, a acessibilidade seja introduzida não apenas na pós-produção, mas seja concebida em todas as etapas da produção.

De acordo com Romero-Fresco (2013),

Ao integrar a tradução audiovisual e a acessibilidade como parte do processo de produção cinematográfica, a produção cinematográfica acessível aborda todos os elementos que os cineastas levam em conta para tornar seus filmes acessíveis não somente para os espectadores com perda auditiva ou visual, mas também para espectadores de outras línguas. Dessa forma, não estamos nos referindo mais a uma minoria, mas a parte maior da audiência. (ROMEROFRESCO, 2013, p. 208. Tradução nossa) 
Concordamos com o autor em sua visão de produto audiovisual que pressupõe que no processo de roteirização sejam previstos os recursos de acessibilidade.

Ao encarar a Ditadura Militar brasileira como uma fase muito importante de nossa história e que deve ser relembrada para que adolescentes, jovens e mesmo adultos não tenham a falsa ilusão de que havia uma "ordem estabelecida", nosso foto-documentário buscou registrar de forma pedagógica e acessível algumas das imagens marcantes que não devem ser esquecidas, seja para os videntes seja para as pessoas com deficiência visual.

\section{Referências}

ABREU, H. O Outro Lado do Poder. 5. ed. Rio de Janeiro: Nova Fronteira, 1979.

ALVES, M.H. Estado e Oposição no Brasil (1964-1984). Rio de Janeiro: Petrópolis, 1984.

ALVES, S. F.; TELES, V. C.; PEREIRA, T.V. Propostas para um modelo brasileiro de audiodescrição para deficientes visuais. Valinhos, São Paulo: Tradução e Comunicação - Revista Brasileira de Tradutores, v. 22, p. 9-29. Disponível em: http://sare.anhanguera.com/index.php/rtcom/article/view/3158/1215. Acesso em: $11 / 08 / 2015$.

BANDEIRA, L. A. M. O Governo João Goulart: as lutas sociais no Brasil, 19611964. 6.ed. Rio de Janeiro: Civilização Brasileira, 1983.

BENECKE, B. Audio-Description. Montréal, Canadá: Meta: journal des traducteurs / Meta: Translators' Journal, vol. 49, $\mathrm{n}^{\circ}$ 1, 2004, p. 78-80. Disponível em http://www.erudit.org/revue/meta/2004/v49/n1/009022ar. Acesso em: $11 / 08 / 2015$. 
BETTO, F. Batismo de Sangue. 10. ed. Rio de Janeiro, Editora Bertrand Brasil, 1991.

CARDOSO, L.C. Construindo a Memória do Regime de 64. Revista Brasileira de História, 1994, v.14, nº 27, p.179-196.

CAVALCANTI, P.C.U.; RAMOS, J. Memórias do Exílio - Brasil, 1964-19??. 1. De muitos Caminhos. São Paulo: Editora Livramento, 1978.

CHAUME, F. Film Studies and Translation Studies: Two Disciplines at Stake in Audiovisual Translation. Montréal, Canadá : Meta: journal des traducteurs / Meta: Translators' Journal, 2004, vol. 49, ${ }^{\circ} 1$, p. 12-24. Disponível em http:// www.erudit.org/revue/meta/2004/v/n1/009016ar.html. Acesso: 11/08/2015.

D’ARAuJO, M. C. et al. (Org.). Visões do Golpe. A Memória Militar Sobre 1964. 2. ed. Rio de Janeiro: Relume-Dumará, 1994.

DREIFUSS, R. A. 1964: A Conquista do Estado. Ação Política, poder e golpe de classe. Traduzido pelo Laboratório de Tradução da Faculdade de Letras da UFMG. 5.ed. Petrópolis: Vozes, 1987.

FICO, C. Versões e Controvérsias sobre 1964 e a Ditadura Militar. Revista Brasileira de História, 2004, v.24. n.47, p.29-60.

FRANCO, E. P. C.2011FRANCO, E. P. C.; FORTUNATO, I.; FARIAS, S. R.; SILVA, M. C. da. Confronting amateur and academic audiodescription: a Brazilian case study. Rio de Janeiro: Tradução em Revista, 2011, v. 11, p. 1-16. Disponível em http://www.maxwell.vrac.puc-rio.br/18863/18863.PDFXXv$\mathrm{mi}=$ DdZvaH7F98oIwxZqHvUFm6nbZHMAQNpu1p2b79Qhif1Pe0hVvdBSk0 5jISUzG15HL7SSgKbz1cpfcIcJWNDhNICwCx6iTc0GjTABELbGxCWbk9Uh WzALidiULpdFDdmW8WzNIKtHmqTIBP1xoBkHPEDB5QhI5EGdCf2k1v3oxx7zN88dKtVA9zcfptZv9FKLVM7xjami8tRWD1anv6ZFGbV7GUDPBnBwbIuuTRO3mH00IbofinVZAR6gMJ608HVk. Acesso em: 11/08/2015.

FURTADO, C. O Brasil Pós- “Milagre”. 6. ed. Rio de Janeiro: Paz e Terra, 1981.

GABEIRA, F. O Que é Isso Companheiro? 14. ed. Rio de Janeiro: Codecri. 1980. 
JORDÃO, F. Dossiê Herzog. Prisão, Tortura e Morte no Brasil. São Paulo: Global Editora, 1979.

KUCINSKI, B. Jornalistas e Revolucionários. Nos tempos da Imprensa Alternativa. São Paulo: Editora Página Aberta, 1991.

LOSNAK, C. J. Ardis da memória: vieses da trajetória política de O Estado e S. Paulo no pós-64. In: CARDOSO, C. M. (Org.). Humanidades em Comunicação: um diálogo multidisciplinar. Bauru: UNESP/FAAC; São Paulo: Cultura Acadêmica, 2005. p.127-141.

MATAMALA, A.; ORERO, P. Designing a course on Audio Description: main competences of the future professional. Antuérpia, Bélgica: Linguistica Antverpiensia. New Series, 2007, v 6, 329-344. Disponível em https://lans-tts.uantwerpen.be/index.php/LANS-TTS/article/view/195/126. Acesso em: 10/11/2015.

MOTTA, L. Definições. Ver Com Palavras: Audiodescrição. Disponível em: http:www.vercompalavras.com.br/definições. Acesso em: 27/08/2014.

NAPOLITANO, M. O golpe de 1964 e o regime militar brasileiro. Apontamentos para uma revisão historiográfica. Contemporânea - Historia y Problemas del siglo XX, 2011, vol. 2, año 2, jun.- dez. 2011, p.209-217.

NAPOLITANO, C.J; LUVIZOTTO, C.K.; LOSNAK, C.J.; GOULART, J.O.; (Org.) O Golpe de 1964 e a Ditadura Militar em Perspectiva. São Paulo: Cultura Acadêmica, 2014.

PORTELA, F. Guerra de Guerrilhas no Brasil. São Paulo: Global Editora, 1979.

RIDENTI, M. O Fantasma da Revolução Brasileira. São Paulo: Editora Unesp, 1993.

ROMERO-FRESCO, P. Accessible filmmaking: Joining the dots between audiovisual translation, accessibility and filmmaking. The Journal of Specialised Translation, 2013, v. 20, p.201-223. Disponível em: http://www.jostrans.org/ issue20/art_romero.pdf. Acesso em: 27/08/2014. 
VLADO- 30 anos depois. Direção: João Batista de Andrade. Europa Filmes, 2006. 1 DVD. 85 min. NTSC, colorido.

SADER, E. Quando Novos personagens entraram em cena. Rio de Janeiro: Paz e Terra, 1988.

SINGER, P. A Crise do "Milagre". Interpretação crítica da economia brasileira. 7. ed. Rio de Janeiro: Paz e Terra, 1982.

SMITH, A.M. Um Acordo Forçado: o consentimento da imprensa à censura no Brasil. Tradução de Waldívia M. Portinho. Rio de Janeiro: Editora FGV, 2000.

SIRKIS, A. Os Carbonários. Memórias da guerrilha perdida. Rio de Janeiro: Editora Globo, 1988, 10ed.

VENTURA, Z. 1968: o ano que não terminou. Rio de Janeiro: Nova Fronteira, 1988.

Recebido em: 04/11/2015

Aceito em: 02/01/2016

Publicado em maio de 2016 